\title{
THE USE OF THE GEOGRAPHICAL INFORMATION SYSTEMS (G.I.S) IN THE GEOLOGICAL - MINERALOGICAL MAPPING OF THE PARANESTI AREA
}

\author{
Karageorgiou M. M. D. ${ }^{1}$, Karymbalis E. ${ }^{2}$ and Karageorgiou D.E. ${ }^{3}$ \\ ${ }^{1}$ Geographer, 62 Amissou str.17123 N.Smyrni, Athens Greece, melaxroini_ka@yahoo.gr \\ ${ }^{2}$ Harokopio University, Department of Geography, karymbalis@hua.gr \\ ${ }^{3}$ Department of Energy Solid Raw Materials, Institute of Geology and Mineral Exploration, Olympic Village, \\ Entrance C 13677 Acharnae Greece.dek@igme.gr
}

\begin{abstract}
The aim of this study is to emphasize the role of the Geographical Information Systems (GIS) technology for the collection, organization, analysis, modeling and presentation of data required for the geological and ore-deposits mapping. As a case study area the region of Paranesti in Northern Greece was selected as it is of exceptional geological and uranium mining interest. For the geological and ore deposit mapping of the study area data derived from analogue maps at various scales (topographical and geological) along with detailed field geological observations and measurements were organized in a spatial database with a common geographical coordinate system utilizing GIS technology. This procedure revealed the relation between the geographical distribution of uranium deposits and the geological structure of the area as well as the effect of the active tectonics.
\end{abstract}

Key words: (GIS) technology, uranium mining, mapping, Paranesti, Northern Greece.

\section{Introduction}

The area of Paranesti is located in the northeastern part of the prefecture of Drama in Northern Greece. The natural relief of the broader area of Paranesti is characterized by intense mountainous morphology. The largest portion is covered by the west part of the Rhodopi mountain chain which is cut by the Nestos River valley and its tributaries.

The region of Paranesti was selected as a case study because it is of exceptional geological and uranium mining interest. For the geological and ore deposit mapping of the study area data derived from analogue maps at various scales (topographical and geological) along with detailed field geological observations and measurements were organized in a spatial database with a common geographical coordinate system. This applied methodology revealed the relation between the geographical distribution of uranium deposits and the geological structure of the area as well as the effect of the active tectonics.

GIS techniques have been used in similar studies such as the implementation of GIS in Santorini volcano for ground deformation analysis (Papageorgiou et al. 2010), the mineral potential map of the Singhbhum copper belt in Jharkhand by P. Sinha et al. (2002) and the creation of a geological database at the area of Kifisia in Athens by A. Zervakou (2004). It was concluded that the role of the Geographical Information Systems (GIS) technology for the collection, organization, analysis, modeling and presentation of data required for the geological and ore-deposits mapping is of great importance. 


\section{The case study area}

The area of Paranesti, located at the northeastern part of the prefecture of Drama, is bordered to the north by Bulgaria, to the south by the prefecture of Kabala, to the west by the Community of Sidironero which belongs to the prefecture of Drama and to the east by the prefecture of Xanthi. It occupies an area of 788.394 acres, which corresponds to the $22,7 \%$ of the total area of the Drama prefecture. The municipality of Paranesti established with the unity of (P.D. 55/7-3-1994, OGJ 39/2133-1994) the Communities of Paranesti, Tholos and Sillis (Prasinada) and is one of the nine LGO (Local Government Organization) of the prefecture of Drama which belongs to the Constituency of the East Macedonia and Thrace. Paranesti's population is 1621 inhabitants, that mainly are refugees came to the area from the Pontos and the Mikra Asia (Asia Minor) since 1922. The capital of the municipality of Paranesti is $39 \mathrm{~km}$ far from the town of Drama and is consisted of 1439 inhabitants.

The area of Paranesti is characterized by intensely mountainous relief morphology. The largest portion is covered by the west part of the mountain chain of Rodopis and is crossed by Nestos River and its tributaries. It is impossible to give an accurate estimation or description of the climate conditions of the area because of the lack of meteorological station within the study area. A satisfactory idea about the climate of the area gives the temperature and rainfall data from the weather station at Sidironero. According to these data for the time period between 1977 and 1987, mean annual rainfall reaches $679 \mathrm{~mm}$ while mean annual temperature is $11,4^{\circ} \mathrm{C}$. The minimum of the temperatures occur during the January and reaches up to $-17^{\circ} \mathrm{C}$ and the maximum at July reaching $38,5^{\circ} \mathrm{C}$. Generally, the climate in this area can be characterized as transitional between Mediterranean and European with the characteristics of the last one to be more intense. The largest part of the region is covered by forests since a small percentage was parceled out to agricultural cultivations, water surfaces, settlements and others land uses.

\section{Methodology (GIS technology) - Results}

Nowadays the main GIS software vendors have created integrated software packages to meet the need of a diverse user community (Longley, 2001). Specifically a GIS provides - among other capabilities - functions for terrain modelling and analysis (Digital Elevation Model creation from various sources, slope calculation, generation of topographic sections, etc.) as well as for geometric and spatial statistical calculations (Chalkias C., 2006).

The system created provides an advanced method to organize, analyze, compute and visualize spatial information and geologic and tectonic features for the geological and deposit mapping and analysis of the area of Paranesti. The core system consists of a commercial GIS software package (ArcGIS) supporting both vector and raster spatial data sets. This software is extended with special external functions (developed in a third generation programming language) implemented for the geological and the deposit analysis. The basic functions include the construction of geo-databases which provide the interaction of various data in a common coordinate system and a common scale. Additionally, functions and operations, among others uses, give the opportunity to create new thematic layers based on the correlation of attributes tables and creation of SQL questions while Spatial join operation is used to combine two or more dataset with respect to a spatial predicate. Finally, there are analysis procedures such as clip, union, intersect where data layers overlay producing new thematic layers.

As mentioned above the specific software that had been used is ArcGIS 9.0 and a prototype system has been developed as an outcome. The architecture of this prototype is illustrated in Fig. 1. The general concept is as follows. The core is a standard GIS. This system was enriched with functions developed especially for the geological and deposit analysis of the area of Paranesti. These functions are operating in relevant spatial datasets incorporated in the system and originated from analogue 


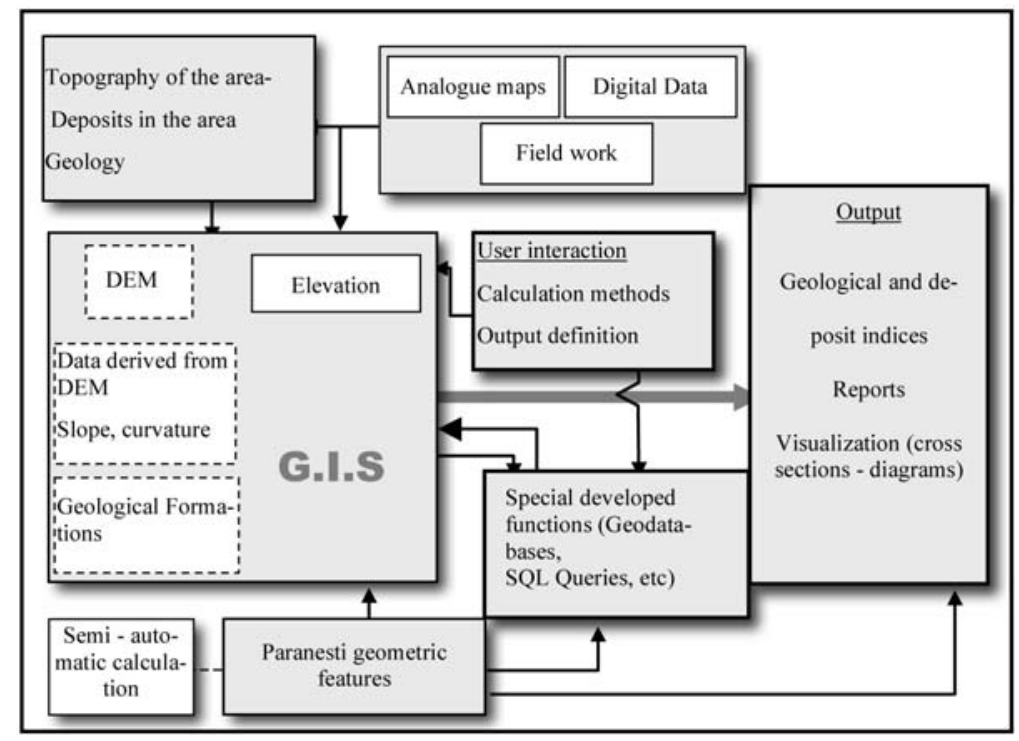

Fig. 1: Architecture of the prototype system.

maps, previous digital datasets and fieldwork. The geology as long as the deposits of the area is estimated through special computational procedures using mainly the DEM of the area geometry. The DEM - which is the main digital model used for the computations - is created by using the internal GIS functionality of the prototype. Features corresponding to Paranesti geometry cannot only manually be input but can also be calculated through semi-automated procedures of the system. The final outputs could be arithmetic features corresponding to specific geological and deposit indices ratios, reports presenting morphology of the area, or advanced visualization.

In the present study for the detailed representation of the topography of the area of Paranesti two topographic maps of 1972 at a scale of 1:50000 obtained from the Greek Army Geographical Service (GAGS) of the area of Paranesti and Mesochori, were used. Additionally, geological maps of the area at the scale of 1:50000 by IGME were used in combination with detailed geological maps produced through extensive fieldwork.

All the analogue maps were scanned and transformed into .jpg files in order to demand less storage space. For the geo-reference of each one of the topographical and geological sheets four control points were choose and their co-ordinates were recorded. Before the geo-referencing the co-ordinates of the control points were transformed from Hatt to EGSA' 87. The aim of this action was to convert all data in the same projection system. The most often used projection system in Greece is the Greek Geodetic Projection System of 1987 (EGSA' 87). While the conversion of the co-ordinates materialized an error occurred in the region of $\pm 0.20 \mathrm{~m}$. The software used for this conversion is the COORD_GR (Siggros, 2002). Generally, during the geo-reference of a map an error occurs due to the position of the cross on the right point of the map. In other words, it depends on whether the new point that has been created on the map has the same co-ordinates with the one on the real map or not. So it's obvious that the total RMS error differs from user to user. Also the mean value of the error has to correspond to the $1 / 4$ of the scale of the map (Chalkias, 2003). This means that for maps at a scale of 1:50000 the error should be less than 15 and for maps 1:5000 scaled should be less than 1 . 
Table 1. The thematic layers that had been created, its attributes and its source.

\begin{tabular}{|l|l|l|l|}
\hline Thematic Layers & Form & Attributes & Data source \\
\hline Contours & Line & Altitude & $1: 50000$ GAGS \\
\hline Geological Formations & Polygon & Geological Formations & $1: 5000$ IGME \\
\hline Geological Lines & Line & GEOLOGY_ID & $1: 5000$ IGME \\
\hline Drillings & Point & Drilling,EGSA87_X,EGSA87_Y & IGME \\
\hline
\end{tabular}

Afterwards, the geographical data of the area was organized into thematic layers in vector and raster form with which a geographical base was created. The attributes and the source of the data are represented in the following Table 1.

The procedure of digitizing was carried out with the head up digitizing method utilizing the respective functions and commands in order to reduce the errors. Then the values of each layer were imported in an attribute table. It was necessary to create the 3D Digital Elevation Model (DEM) in order to represent the general morphology and the curvature of the area. The DEM was created using appropriate vector data (contour lines) and specialized procedures (ANUDEM algorithm) in the framework of the used GIS. A number of secondary geographical variables, which are very significant in morphometric and geological analysis, were derived from the DEM. These variables are related to elevation measurements, slope, volumetric computations, geological formation outcrop and tectonic features such as faults.

A series of drillings were developed in the area of Paranesti by the Institute of Geology and Mineral Exploration (IGME) in order to study the geological and deposit characteristic of the area (Pergamalis et al., 1998). The process of creating the drillings began in December of 1978 and completed in December of 1996. The results were visualized in a map at a scale of 1:5000. The map was created between 1993 and 1996. It must be noted that the co-ordinates of the drillings were saved in a digital Excel file. This file was transformed in a data base (Access). Using the software ArcGIS 9.0 and the command Add xy data all the data and all the co-ordinates of the drillings are embodied in the program prepared to be computed.

According to the map the drillings were performed at the northwest and the southeast part of the area where the formations of "granite type Fteroto" and "granite type Dipotama" are developed. This happened because the aim of the exploration, part of which was the execution and the valuation of the drillings which was held by the Institute of Geology and Mineral Exploration (I.G.M.E.), was the discovery of uranium in this area. It was well-known, from previous explorations (regular and methodical stages), that uranium developed in these two geological formations and not in the "Middle type granite" (Pergamalis et al., 1998).

\section{Geological Mapping}

The methodology of combining all the data utilizing Geographical Information Systems lead to the construction of the following map (Fig. 2). This map depicts all the geological formations that seem to have the greatest mining interest in the area.

This map shows that in the area of Paranesti granite types are developed which can be grouped in three sub-categories: "granite type Fteroto", "granite type Dipotama", "granite Middle type". Additionally, the area is composed of volcanic rocks, sendimentary-volcanic series, metamorphic rocks, limestone and limestone debris. The following table (Table 2) includes all the geological formations that the area consists of as well as the total area that each one of these formations occupies $\left(\right.$ in $^{2}{ }^{2}$ ). 


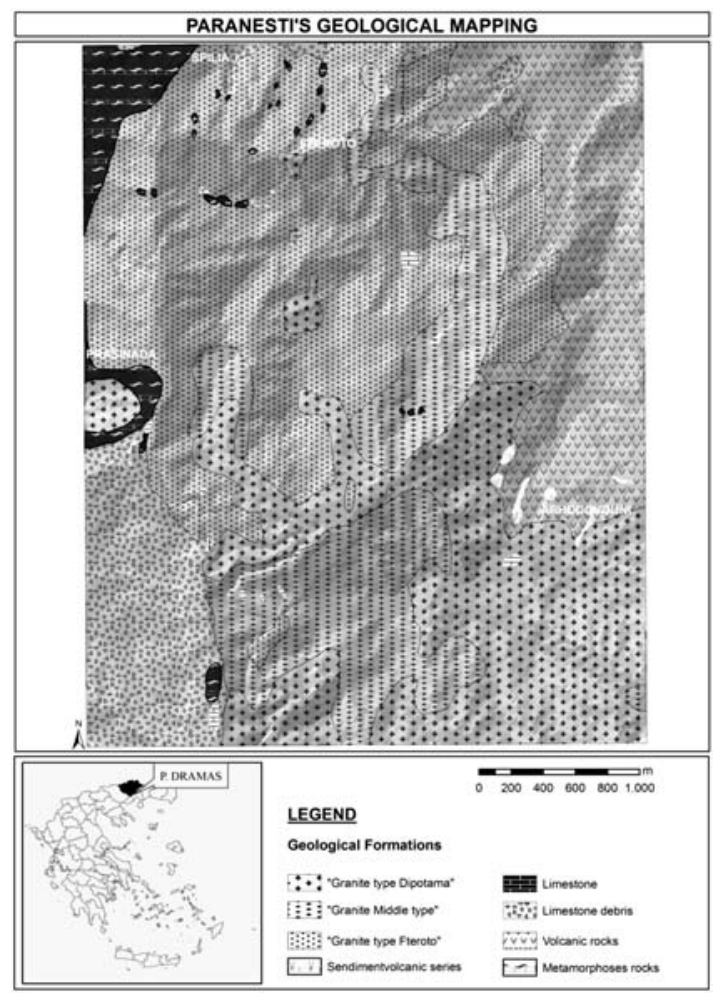

Fig. 2: The representation of all the geological formations which appear in the area of Paranesti.

\begin{tabular}{|l|l|}
\hline Geological Formations & Area $\left(\mathbf{m}^{2}\right)$ \\
\hline "Granite type Fteroto" & $5.150 .951,901$ \\
\hline "Granite type Dipotama" & $3.300 .367,627$ \\
\hline "Granite Middle type" & $2.571 .148,089$ \\
\hline Volcanic rocks & $2.387 .990,000$ \\
\hline Limestone debris & $1.401 .598,009$ \\
\hline Metamorphoses rocks & $492.907,886$ \\
\hline Limestone & $39.537,081$ \\
\hline
\end{tabular}

Table 2. The geological formations of the Paranesti region and the area occupied by each one of them.

The Comparative observation of Fig. 2 and Table 1 shows that the largest area of Paranesti, which is $5.150 .951,901 \mathrm{~m}^{2}$, is occupied by the formation called "granite type Fteroto" while the total area of "granite type Dipotama" and "granite Middle type" is 3.300.367,627 $\mathrm{m}^{2}$ and 2.571.148,089 $\mathrm{m}^{2}$ respectively. Additionally, 2.387.990,000 $\mathrm{m}^{2}$ of the study area consists of volcanic rocks while the limestone debris and the metamorphoses rocks cover an area of 1.401.598,009 $\mathrm{m}^{2}$, and 492.907,886 $\mathrm{m}^{2}$ respectively. Finally a small part of the area of Paranesti is composed of limestone formations and the sedimentary-volcanic series with areas of 39.537,081 $\mathrm{m}^{2}$ and $30.242,099 \mathrm{~m}^{2}$ respectively. It has to be mentioned that this granite types rocks (the "granite type Fteroto", the "granite type Dipotama" and the "Middle type"), which cover the wider area of Paranesti, are characterized as acid rocks. This is the main reason that leads the geologists to perform exploration activities for examining the opportunity of the existence of economical deposit of uranium. 


\section{Conclusions}

The geology as long as the deposit of the area is estimated through special computational procedures using mainly the DEM of the area geometry. A series of drillings were developed in the area of Paranesti in order to study the geological and deposit characteristic of the area. A geological map of the study area was constructed through IGME geological previous maps and extensive detailed fieldwork mapping utilizing ArcGIS 9.0 software. The "granite type Fteroto" covers the largest part of the Paranesti area, then follow the "granite type Dipotama" and the "granite Middle type". All these formations are of great economically importance for the deposit of uranium.

The methodology followed in this study is based on GIS technology. The use of GIS in all sectors of geo-sciences, gives solutions in problems that are related with the geological environment. Data procedure in the analytical context of GIS can produced useful variables and estimations. A fundamental element of a GIS is data integration which includes a common geographical reference system, common spatial and temporal coverage, and similar scale and quality of the data.

At the sector of digital cartography the interest focuses on the creation of a spatial database from where user can produce a geological map. Similarly at the sector of mineralogy the aim is to create a geodatabase where details for mineral outcrops can be stored. In this way, researches for mineral exploitations of oil and gas can be supported. Finally, at the sector of seismology GIS offer the possibility of, observing and earthquakes and researching the relation between earthquake events and fault zones. All these applications are owed in the particularities that GIS present. The most basic advantage of the GIS philosophy is the usefulness of the spatial data where the significance of spatial is incorporated with the attributes of data. Using spatial data is given the possibility for further analysis to qualitative data as long as quantitative.

GIS is not only a mean of producing maps but also a new completed technology essential for the analysis and the study of space and the decision-making concerning the terrain, the environment and the human.

\section{References}

Chalkias C. 2003. Geographical Information Systems II (lecture notes), Harokopio University of AthensDepartment of Geography.

Chalkias C. 2006. Terms and Meanings of Geographical Information, Harokopio University of AthensDepartment of Geography.

Din A. 1993. Interdisciplinary Research directions of GIS, Mapping Awareness \& GIS in Europe, vol 7 , no 2, pp. 11-14.

Haines Young, R. 1990. GIS for Environmental Management, Mapping Awareness, vol 4, no 9, pp 51-54.

Longley 2001. Geographic Information Systems and Science, Wiley, England.

Papageorgiou E., Vasilopoulou S., Lagios E., 2010. Implementation of GIS in Santorini volcano for ground deformation analysis. $8^{\text {th }}$ Pan-hellenic Geographical Conference. Athens Greece, vol 1, pp 166-174.

Pergamalis, Ph., Papachristopoulos, S., Karageorgiou, E., D. and Koukoulis, A., 1998. Geological features of uranium and Rare Earths ores of Paranesti Drama areas, Bulletin of Geological Society of Greece, vol. XXXII No3 pp.145-155.

Siggros Y. 2002, Transforming coordinates of the Greek spatial data, Athens, Greece (http://users. auth.gr/kvek/coords gr.zip).

Sinha P., Nath M., De S., Misra R. 2002. Mineral potential map by a knowledge driven GIS modelling: An example from Singhbhum copper belt, Jharkhand India (http://www.gisdevelopment. net/application/geology/mineral/geom0007.htm).

Zervakou A. 2004. Educational material for applying GIS in geology. Theory and Practice. The case study of Kifissia. NTUA, Greece. 